\title{
OPTICAL EFFECTS PRODUCED BY RUNNING ONBOARD ENGINES OF LOW-EARTH-ORBIT SPACECRAFT
}

\author{
A.B. Beletsky, A.V. Mikhalev, V.V. Khakhinov, V.P. Lebedev \\ Institute of Solar-Terrestrial Physics SB RAS, Irkutsk, Russia, beletsky@iszf.irk.ru, \\ mikhalev@iszf.irk.ru,khakhin@iszf.irk.ru,lebedev@iszf.irk.ru
}

This paper presents results of optical observations made during Radar-Progress Experiment performed on April 17, 2013 and July 30, 2014 after approach-correction engines (ACE) of Progress M-17M and Progress $M-23 M$ cargo spacecraft in the thermosphere had been started. A region of enhanced emission intensity was recorded during engine operation. This may have been related to the scatter of twilight solar emission along the cargo spacecraft exhaust and to the emergence of additional atomic oxygen [OI] emission at $630 \mathrm{~nm}$. The maximum dimension of the observed emission region was $\sim 330-350 \mathrm{~km}$ and 250-270 km along and across the orbit respectively. For the first time after ACE had been started, an expansion rate of emission region was $\sim 7$ and $\sim 3.5 \mathrm{~km} / \mathrm{s}$ along and across the orbit respectively. The maximum intensity of the disturbance area for Progress $M-17 M$ is estimated as $\sim 40-60 R$ at $2 \mathrm{~nm}$. Progress M-23M Space Experiment recorded a minor disturbance of atmospheric [OI] $630.0 \mathrm{~nm}$ emissions, both in near and in far cargo spacecraft flight paths, which might have been associated with the ACE exhaust gas injection.

Keywords Airglow $\cdot$ Ionosphere $\cdot$ Spacecraft

\section{INTRODUCTION}

Optical effects caused by spacecraft (SC) flights and their running approach correction engines (ACE) are divided into several types depending on mechanisms, heights, and spatial scales of their manifestation [Adushkin et al., 2000; Platov et al., 2003]. Mechanisms of ACE impact on Earth’s atmosphere and ionosphere, which occurs with optical effects, are directly associated with cargo spacecraft exhaust jets containing gas and dispersed components, sunlight scattering by them [Adushkin et al., 2000], modification of the atmosphere and ionosphere by ACE exhaust jets [Mendillo et al., 1975; Karlov et al., 1980], hydrodynamic disturbances such as acoustic gravity waves [Karlov et al., 1980; Mikhalev and Ermilov, 1997; Mikhalev, 2011], etc. Most optical effects are observed in the troposphere and stratosphere when their brightness is relatively high [Platov et al., 2003].

This paper presents optical observations made during the Radar-Progress active space experiments on April 17, 2013 and July 30, 2014 after start of ACE of the Progress-M cargo spacecraft in the thermosphere. 


\section{RADAR-PROGRESS ACTIVE SPACE EXPERIMENT}

The space experiment SE "Investigation of ground-based observations of reflection characteristics of ionospheric plasma irregularities generated by onboard engines of Progress cargo spacecraft" (code "Radar-Progress”) has been performed since 2007. Until 2010, this experiment was called Plasma-Progress SE [Lebedev et al., 2008; Potekhin et al., 2009; Khakhinov et al., 2010, 2012, 2013]. Participating organizations: FSUE TSNIIMASH, ISTP SB RAS, and RSC Energia.

The Radar-Progress space experiment is held during Progress SC autonomous flights upon completion of its main mission of delivering cargo to the International Space Station (ISS). A SE session is performed during an SC flight in the field of view of the Irkutsk Incoherent Scatter Radar (IISR) [Khakhinov et al., 2009]. The onboard liquid jet ACE is activated. We employ unique ground-based scientific facilities and equipment of the ISTP SB RAS Common Use Center (CUC) “Angara” [http://ckpangara.iszf.irk.ru/html/history.html].

During or immediately after a SE session, we determine heliogeophysical and weather conditions: solar activity, geomagnetic conditions, background parameters of the ionosphere, light conditions (solar zenith angle), cloudiness.

We pre-plan governing conditions for each SE session: orbital height, direction of an exhaust velocity vector, type and duration of ACE operation. The last ones define the mass of burned fuel and the amount of exhaust gases injected into the ionosphere. The ACE in use burns $1 \mathrm{~kg}$ of liquid fuel per second. Working for $11 \mathrm{~s}$, the ACE injects exhaust jets from $11 \mathrm{~kg}$ of fuel into the ionosphere along the arc of the SC orbit more than $80 \mathrm{~km}$ long. Such insignificant effects on ionospheric plasma, comparable in strength to natural sources of disturbances, and the pre-planned conditions for each session constitute a distinguishing feature of the ongoing SE.

EXPERIMENTAL CONDITIONS, EQUIPMENT AND OBSERVATIONAL METHODS

Conditions of the April 17, 2013 SE session (Progress M-17-M SC). Heliogeophysical conditions: very quiet geomagnetic conditions, the solar activity index $F 10.7=107.1$, the maximum electron density $5.87 \cdot 10^{5} \mathrm{~cm}^{-3}$ was at $301 \mathrm{~km}$. Meteorological conditions favored photometric measurements. Design conditions: the SC orbital height was $412 \mathrm{~km}$, the duration of ACE operation was 9 s (13:24:38--13:24 47 UT), which corresponds to combustion of $9 \mathrm{~kg}$ of fuel; the direction of fuel jets was toward IISR beam. Optical equipment is installed at $120 \mathrm{~km}$ from IISR, at the ISTP SB RAS Geophysical Observatory (GO) $\left(52^{\circ} \mathrm{N}, 103^{\circ} \mathrm{E}\right)$.

Conditions of the July 30, 2014 SE session (Progress M-23M SC). Heliogeophysical conditions: quiet geomagnetic conditions, the solar activity index $F 10.7=157$, the maximum electron density $2.8 \cdot 10^{5} \mathrm{~cm}^{-3}$ 
was at $352 \mathrm{~km}$. Meteorological conditions favored photometric measurements. Design conditions: the SC orbital height was $418 \mathrm{~km}$, the duration of ACE operation was 8 s (18:11:10-18:11:18 UT), which corresponds to combustion of $8 \mathrm{~kg}$ of fuel; the direction of fuel jets was toward GO.

The estimated molar percentage of exhaust gases:

- $\mathrm{H}_{2} \mathrm{O}=2.932 \cdot 10^{-1}, \mathrm{~N}_{2}=2.676 \cdot 10^{-1}, \mathrm{CO}=1.932 \cdot 10^{-1}$,

- $\mathrm{H}_{2}=1.877 \cdot 10^{-1}, \mathrm{CO}_{2}=4.946 \cdot 10^{-2}, \mathrm{H}=8.524 \cdot 10^{-3}$,

- $\mathrm{NO}=3.392 \cdot 10^{-4}, \mathrm{OH}=2.853 \cdot 10^{-5}, \mathrm{O}_{2}=2.744 \cdot 10^{-5}$,

- $\mathrm{O}=1.391 \cdot 10^{-5}, \mathrm{~N}=5.376 \cdot 10^{-8}$.

- gasing rate is $\sim 2.8 \mathrm{~km} / \mathrm{s}$,

- density is $\sim 2.7 \cdot 10^{-3} \mathrm{~kg} / \mathrm{m}^{3}$,

- temperature is $\sim 590 \mathrm{~K}$.

We have used the following optical equipment: spectrograph SATI-1M [http://atmos.iszf.irk.ru/ru/ground-based/spectr], a wide-angle color CCD camera [http://atmos.iszf.irk.ru/ru/ground-based/color], a wide-angle optical system KEO Sentinel designed to observe the spatial distribution of [OI] $630 \mathrm{~nm}$ emission intensity. The July 30, 2014 SE session additionally used a high-aperture monochromator MDR-2 equipped with an image intensifier tube (IIT) and a CCD camera.

The SATI-1M spectrograph was developed from the ISP-51 spectrograph (LOMO design) and from the color CCD matrix SONY ICX285AQ (camera Videoscan-285 produced by NPO Videoscan, [http://videoscan.ru]). In order for the matrix dimensions to agree with the dimensions of the spectra in the focal plane, a Gelios-40 lens ( $F=85 \mathrm{~mm}, 1: 1.5)$ is installed as a camera lens. The entrance spectrograph slit is illuminated by the Jupiter-3 lens $(F=50 \mathrm{~mm}, 1: 1.5)$. The operating spectral bandwidth of the spectrograph is $400-700 \mathrm{~nm}$, exposure time is $260 \mathrm{~s}$, the optical SATI $1 \mathrm{M}$ axis points northward with a zenith angle of $\sim 67^{\circ}$.

The Filin-1C camera was developed from the cooled color CCD matrix Kodak KAI-11002 (camera Videoscan-11002 designed by NPO Videoscan, [http://videoscan.ru]). As the entrance lens we use the Mir-20 lens ( $\mathrm{F}=20 \mathrm{~mm}, 1: 3.5)$. The camera has a thermostable case, a rotating turret, and is pointed toward the northern sky, toward the celestial pole. The angular field of view of the Filin-1C camera is $\sim 90^{\circ}$, the exposure time is $300 \mathrm{~s}$, the matrix resolution is $4004 \times 2671$ pixel.

The wide-angle optical system KEO Sentinel centered on the atomic oxygen line [OI] $630 \mathrm{~nm}$ is produced by KEO Scientific Ltd [http://keoscientific.com/space-science-imagers.php\#SENTINEL]. The field of view of the optical system is $145^{\circ}$; the half-width of the interference filter $(630 \mathrm{~nm})$ is $\sim 2 \mathrm{~nm}$; the optical system is directed to the zenith; the exposure time is $30 \mathrm{~s}$; the binning is 4 . Frames are taken continuously, one by one. The technical pause between frames is $\sim \mathrm{s}$.

The spectrograph developed from the high-aperture monochromator MDR-2 (MDR-2 spectrograph), IIT, and CCD matrix is designed to record the spectral composition of airglow at high temporal resolu- 
tion. Its primary purpose is to study disturbances in the main emission lines and bands (OI 557.7, OI 630.0, NaI 589.0-589.6 nm, etc.), continuum, and individual weak emissions during heliogeophysical disturbances of different nature. The viewing direction is the zenith; the field of view is $\sim 10^{\circ}$; the exposure time is $10 \mathrm{~s}$; frames are taken continuously.

The solar zenith angle during ACE operation in the April 17, 2013 SE was - $100^{\circ}$, i.e. observations were carried out under nautical twilight conditions.

For the July 30, $2014 \mathrm{SE}$, this angle was $\sim-109^{\circ}$, i.e. observations were made in conditions close to astronomical twilight.

The Progress M-17M and Progress M-23M SC fight paths did not fall within the field of view of the SATI-1M spectrograph and the wide-angle color CCD camera. These devices are used for patrol observations of natural (background) nightglow and for monitoring heliogeophysical disturbances, which require fixed orientation of these devices. In this work, they are employed to monitor the atmosphere transparency, the dynamics of the main emission lines of the upper atmosphere, and to record disturbances in atmospheric regions distant from the injection of Progress M-17M and Progress M-23M SC exhaust gases.

\section{OBSERVATIONAL RESULTS}

\section{Optical observations (KEO Sentinel optical system)}

April 17, 2013 experiment

While ACE was running, the zenith of the lower boundary of the atmosphere still illuminated by the Sun was at $\sim 140 \mathrm{~km}$. Thus, SC and its surrounding area were illuminated by direct solar radiation. This favored light scattering by gas and dispersed components of ACE fuel jets. On the other hand, these conditions have already allowed the detection of airglow in order to evaluate optical effects observable during ionospheric modification [Mendillo, Baumgardner, 1982], in particular in the 557.7 and $630 \mathrm{~nm}$ atomic oxygen emission lines.

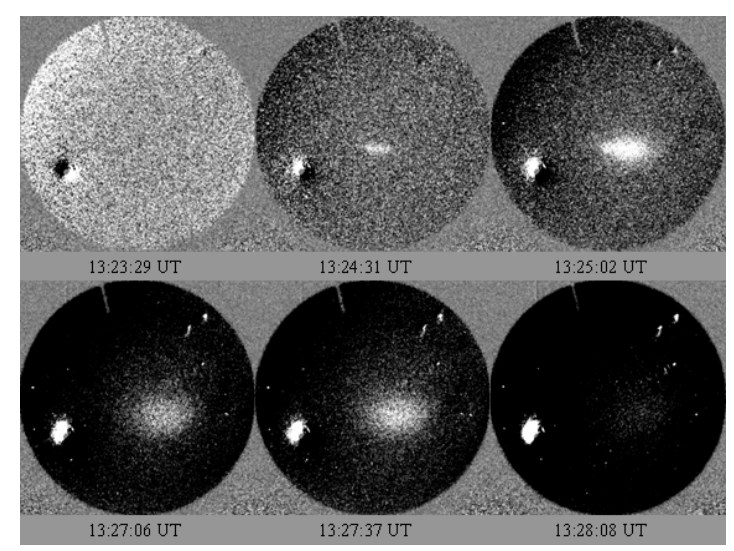

Figure 1. Sequence of processed frames taken by the KEO Sentinel optical system in the $630 \mathrm{~nm}$ emission line on April 17, 2013 The ACE running time is 13:24:38-13:24:47 UT 
Figure 1 presents observational data acquired by the all-sky camera at $630 \mathrm{~nm}$ during ACE operation. The starting time of exposure of respective frames is specified. Images were obtained by subtracting the key frame, taken just before ACE ignition, from current frames. The bright spot in the bottom left part of the images is an image of the Moon, broadened due to the blooming effect. The processing technique is described in more detail in [Mikhalev et al., 2016].

From the frame with the starting time of exposure at 13:24:31 UT, including the time of ACE running, to the south-east of the center of images (zenith) there is a region of enhanced emission, which in subsequent moments extends along and across the SC flight path. This region was observed for a total of $\sim 5 \mathrm{~min}$. According to preliminary estimates, with the height of the SC flight path of $\sim 400 \mathrm{~km}$ the rate of emission expansion for the first 60 seconds after ACE ignition was $\sim 7 \mathrm{~km} / \mathrm{s}$ and $\sim 3.5 \mathrm{~km} / \mathrm{s}$ along and across the SC orbit respectively. Maximum dimensions of the region were observed in $\sim 120-150 \mathrm{~s}$ and were $\sim 350$ and $\sim 250 \mathrm{~km}$ along and across its orbit respectively.

Brightening of the disturbed part of the image at a maximum relative to the surrounding background was $\sim 20 \%$. Given that the natural intensity of atmospheric emission at the zenith at early night is usually 200-300 R (this is consistent with the measurement data on the $630 \mathrm{~nm}$ emission intensity acquired by SATI-1M in the northern sky (Figure 3)), we can estimate the equivalent maximum disturbance intensity at $40-60 \mathrm{R}$ in the $2 \mathrm{~nm}$ spectral bandwidth of the interference filter.

\section{July 30, 2014 experiment}

Figure 2 shows a sequence of frames similar to that presented in Figure 1. From the frame with the starting time of exposure at 18:11:19 UT (Figure 2), taken immediately after ACE ignition (18:11:18 UT), there is a region of enhanced emission, which in subsequent moments extends along and across the SC flight path.

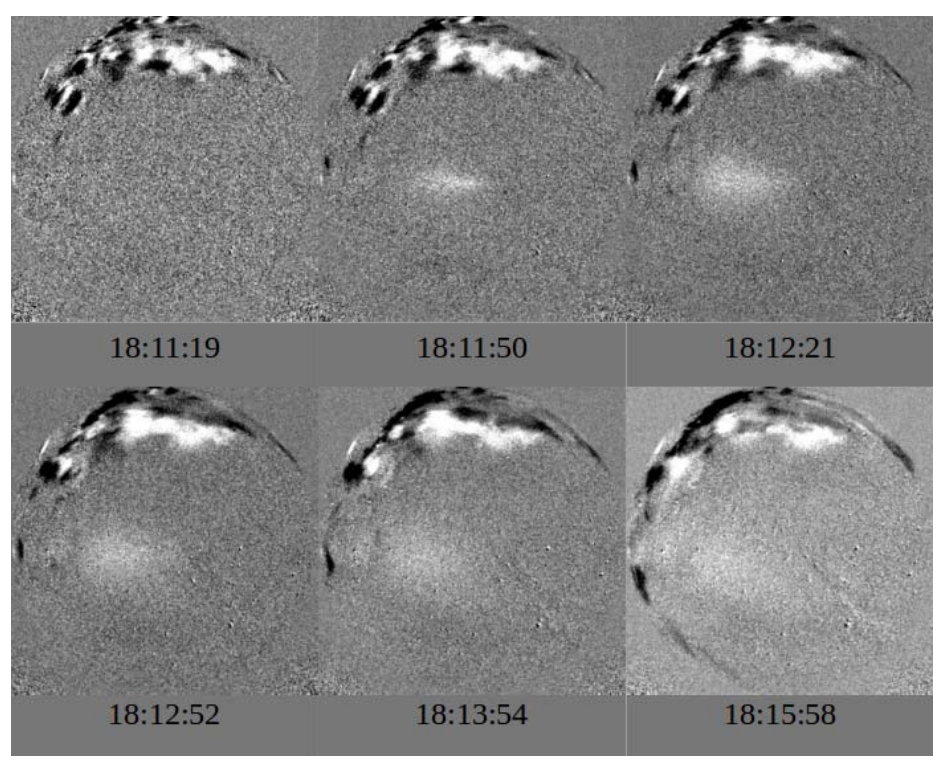

Figure 2. Sequence of processed frames taken by the KEO Sentinel optical system in the $630 \mathrm{~nm}$ emission line on July 30, 2014. The ACE running time is 18:11:10-18:11:18 UT 


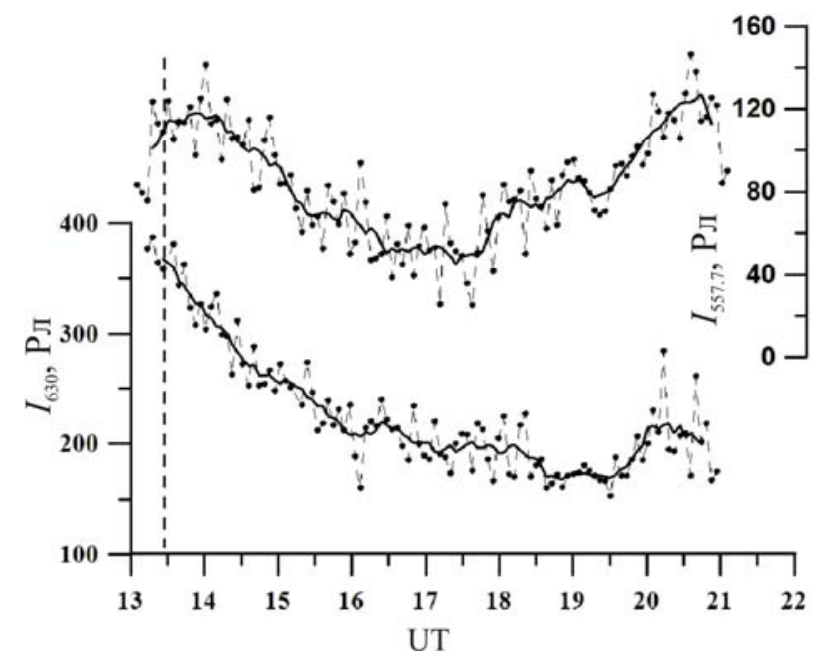

Figure 3. Variations in the intensity of [OI] 557.7 and $630.0 \mathrm{~nm}$ emission lines during the night on April 17/18, 2013. The vertical dashed line indicates the time interval of ACE running

According to preliminary estimates, the expansion rate, maximum observed dimensions, and total time of observation are similar to those determined for the April 17, 2013 SE session.

\section{Spectral observations (SATI-1M and MDR-2 spectrographs)}

April 17, 2013 experiment

Figure 3 presents observations of the airglow intensity in the atomic oxygen emission lines [OI] $557.7 \mathrm{~nm}$ (heights of the emission are $\sim 85-115 \mathrm{~km})$ and [OI] $630.0 \mathrm{~nm}(\sim 180-300 \mathrm{~km})$ during the April 17/18, 2013 night as inferred from SATI-1M data. These lines are dominant emissions that are normally recorded in ionospheric modification experiments during SC ACE operation [Mendillo, Baumgardner, 1982]. The natural airglow was observed at $\sim 235 \mathrm{~km}$ (for the height of the maximum spontaneous emission at $557.7 \mathrm{~nm})$ and $\sim 600 \mathrm{~km}(630.0 \mathrm{~nm})$ northward of the zenith. In Figure 3, the vertical dashed line indicates the time interval of ACE operation. The preliminary analysis of 557.7 and $630 \mathrm{~nm}$ emission intensity variations does not allow us to identify disturbances produced by ACE ignition, which far exceed natural variations of these emissions. This leads to the tentative conclusion that there is no largescale ionospheric modification in this SE session.

\section{July 30, 2014 experiment}

In the July 30, 2014 experiment, we employed the SATI-1M spectrograph and the MDR-2 spectrograph that was oriented toward the near-zenith region of the sky close to the Progress M-23M SC flight path. This provided the possibility of comparing the behavior of the $630 \mathrm{~nm}$ emission intensity for the first minutes after ACE was cut off, using the two differently directed spectral instruments.

Figure 4 illustrates $630 \mathrm{~nm}$ emission intensity variations as inferred from observational data acquired by the SATI-1M and MDR-2 spectrographs. ACE was started in the second half of the night against the natural decrease in the $630 \mathrm{~nm}$ emission intensity. Unlike the SATI-1M spectrograph with the exposure time of $260 \mathrm{~s}$, the exposure time of the MDR-2 spectrograph was $10 \mathrm{~s}$. Perhaps this may explain the fairly large signal variations in the MDR-2 spectrograph channel. Nevertheless, by smoothing initial data (averaging over 5 points for 
Optical effects produced by running onboard engines...

MDR-2 and over 3 points for SATI-1), we can find tendencies for minor increases in $630 \mathrm{~nm}$ emission intensities after ACE was cut off, using both the devices. Maximum intensities were observed in 7-12 min for MDR2 data and in 14-18 min for SATI-1M data.

\section{RESULTS}

Geophysical conditions of observations, typical lifetimes, and spatial dimensions of observed optical structures allow us to examine two mechanisms of the observed optical effects.

The former one may be associated with the scattering of sunlight by ACE exhaust jets [Adushkin et al., 2000; Platov et al., 2003]. Platov et al. [Platov et al., 2011] note that the most important factor determining the intensity of such effects is the presence of dispersed particles. The dispersed particles originate from vapor and carbon dioxide condensation in an exhaust jet.

The latter mechanism is related to ionospheric modification and emergence of additional radiation in the [OI] $630 \mathrm{~nm}$ atomic oxygen emission [Mendillo, Baumgardner, 1982]. The analysis of data on spatial distribution of the [OI] $630 \mathrm{~nm}$ emission, acquired by the wide-angle optical system KEO Sentinel during Progress M-17M and Progress M-23M SC ACE operation enables us to reliably identify regions with enhanced emission.

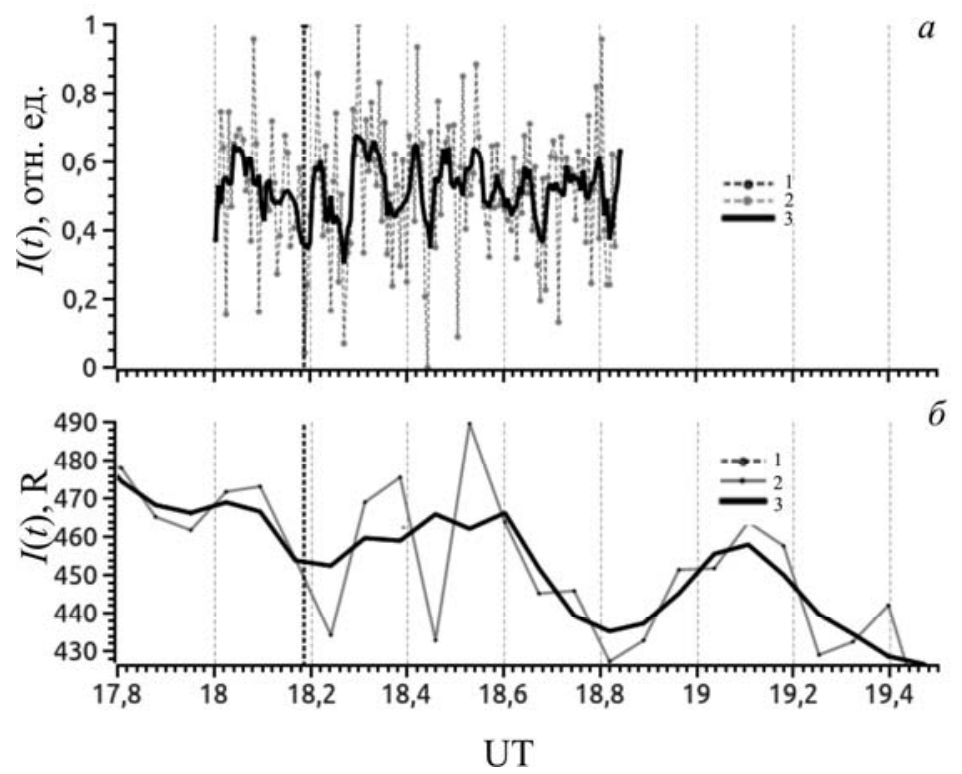

Figure 4. Variations in the $630 \mathrm{~nm}$ emission intensity as inferred from observational data obtained by the MDR-2 (a) and SATI-1M (b) spectrographs. Line 1 is the time interval of ACE operation, line 2 indicates initial data; line 3 marks average data (5 points for MDR-2 data ( $a$ ) and 3 points for SATI1-M data $(b)$ )

The maximum observed dimensions of the region are $\sim 330-350 \mathrm{~km}$ and $\sim 250-270 \mathrm{~km}$ along and across the orbit respectively. The rate of emission expansion at the first moments after the start of ACE is $\sim 6-7 \mathrm{~km} / \mathrm{s}$ and $\sim 3-3.5 \mathrm{~km} / \mathrm{s}$ along and across the orbit respectively. 
Supersonic extension ( $1-4 \mathrm{~km} / \mathrm{s})$ of optical structures in the upper atmosphere during ACE operation has been observed previously [Vetchinkin et al., 1993; Tagirov et al., 1995]. One of the mechanisms of propagation of ACE exhaust jets in the upper atmosphere is considered to be diffusion. In the region covered by diffusion, ACE exhaust jets, in addition to the normal process of mixing with the atmosphere, can lead to changes in aerodynamic processes at injection heights and occur with ionospheric modification, including changes in airglow in the main emission lines and bands [Adushkin et al., 2000].

Data acquired by the optical system KEO Sentinel does not allow us to divide effects of the light scattering by ACE exhaust jets and ionospheric modification (630 nm emission increase). Of particular interest in this regard are the spectral observations in the experiment with the Progress M-23M SC and the results obtained previously by other authors in active experiments with injection of large masses of burned fuel.

Thus, according to [Biondi, Simpler, 1984], the injection of $\sim 2.7 \cdot 10^{26} \mathrm{CO}_{2}$ and $7.4 \cdot 10^{26} \mathrm{H}_{2} \mathrm{O}$ molecules into the ionosphere at $\sim 323 \mathrm{~km}$ led to the formation of an enhanced emission region. Within 2 min after the injection, the $630 \mathrm{~nm}$ emission increased up to $400 \mathrm{R}$, and in $3 \mathrm{~min}$ the enhanced emission region expanded to a diameter of $250 \mathrm{~km}$.

In the experiment described in [Bernhadt et al., 1986], $18 \mathrm{~kg}$ of $\mathrm{SF}_{6}$ were injected at a height of $\sim 350 \mathrm{~km}$. This resulted in the formation of a $56 \mathrm{~km}$ enhanced emission region. The OI emission at the 777.4 and $630 \mathrm{~nm}$ lines exceeded the background by 150 and $15 \mathrm{R}$ respectively; the maximum intensities were observed 2 min after the injection.

In [Mendillo, 1980; Mendillo et al., 1981], the authors describe the results of the study of ionospheric effects of the HEAO-C spacecraft launch. On launch, the spacecraft injected $7 \times 10^{29} \mathrm{H}_{2} \mathrm{O}$ and $\mathrm{H}_{2}$ into the atmosphere, thus leading to the formation of an ionospheric hole, which extended its influence over an area of $(1 \div 3) \cdot 10^{6} \mathrm{~km}^{2}$. The hole was located along the spacecraft track at 2000-3000 km to the east of the launch site; its transverse size was 600-1000 km. In the center of the hole at the first two minutes, more than $80 \%$ of electrons and ions disappeared. The integral vertical emission at a wavelength of $630 \mathrm{~nm}$ in the hole was $8300 \mathrm{R}$ (before the launch of the spacecraft, it was $100 \mathrm{R}$ ). The $557.7 \mathrm{~nm}$ emission increased from 300 to $900 \mathrm{R}$. The maximum intensities were observed a few minutes after the SC launch, and in 10-20 min the intensities returned to their baseline values. A similar situation was noted in [Mendillo, Baumgardner, 1982] which took place during the NOAA-C SC launch followed by a burst of the $630 \mathrm{~nm}$ emission at a maximum up to $9 \mathrm{kR}$.

Of key importance for us in the results obtained in the above studies are the characteristic dimensions of enhanced emission regions and the dynamics of optical structures and atmospheric emissions.

So, according to the reported data, sizes of the disturbed region transverse to the SC flight path can be as large as 600-1000 km, which is comparable to the distance from the zenith direction of the region, where the $630 \mathrm{~nm}$ emission was detected by the SATI-1M spectrograph ( 600 km). In our case, with the 
Optical effects produced by running onboard engines...

recorded velocities ( $\sim 3 \mathrm{~km} / \mathrm{s}$ ) of disturbances across the SC flight path, it takes the disturbances $\sim 3$ min or more to get the working area of the SATI-1M spectrograph (if the propagation velocity decreases).

According to the reported data, the emission in the injection zone peaked two or more minutes after the injection of exhaust gases. The characteristic lifetime of regions with enhanced $630 \mathrm{~nm}$ airglow ranges from one to tens of minutes.

The time delays of $630 \mathrm{~nm}$ emission intensity maxima recorded on July 30, 2014 (7-12 min for the near-region and 14-18 min for the far region) and the characteristic lifetime of the disturbance in the 630 nm emission intensity ( 5-15 min) are comparable by orders of magnitude to the published data acquired in similar experiments with the injection of large amounts of chemicals into the upper atmosphere and with the ionospheric modification.

In interpreting spectral observations, of particular importance is yet another experimental fact such that several Radar-Progress experiments detected an electron density decrease [Khakhinov et al., 2013] characteristic of ionospheric modification. This is attributed to the reaction of dissociative recombination of molecular ions $\left(\mathrm{H}_{2} \mathrm{O}^{+}, \mathrm{O}_{2}{ }^{+}, \mathrm{OH}^{+}\right)$, which may arise from injection of $\mathrm{H}_{2} \mathrm{O}, \mathrm{H}_{2}, \mathrm{CO}_{2}$ and $\mathrm{OH}$ molecules composing ACE exhaust gases .

Hence, we can state that the nature of the observed peculiarities of OI $630 \mathrm{~nm}$ emission variations in the spectral observations on July 30, 2014 does not exclude that they might be caused by the injection of ACE exhaust gases. Indeed, confirmation of this result requires further investigations in order to determine the most favorable geophysical conditions for this effect and, in particular, to interpret the absence of this effect on April 17, 2013.

\section{CONCLUSION}

The analysis of optical observations carried out during sessions involving the Progress M-17M SC on April 17, 2013 and the Progress M-23M SC on July 30, 2014 allows for the following conclusions.

1. During ACE operation, we detected regions with enhanced emission, which might have been caused by the scattering of twilight solar radiation by ACE exhaust gases along the SC flight path or by the appearance of an additional airglow in the [OI] $630 \mathrm{~nm}$ atomic oxygen emission. The maximum observed dimensions of the emission region were $\sim 330-350$ and $\sim 250-270 \mathrm{~km}$ along and across the orbit respectively. The rate of emission expansion at the first moments after the start of ACE was $\sim 6-7 \mathrm{~km} / \mathrm{s}$ and $\sim 3-3.5 \mathrm{~km} / \mathrm{s}$ along and across the orbit respectively. The maximum intensity of the disturbed region for the Progress M-17M SC is estimated at 40-60 R in the $2 \mathrm{~nm}$ spectral bandwidth.

2. In the SE session with Progress M-23M on July 30, 2014, we recorded minor disturbances of atmospheric [OI] $630.0 \mathrm{~nm}$ emissions in the near and far regions from the SC flight path, which might have been caused by the injection of ACE exhaust gases. 
The work was carried out using the scientific equipment of the ISTP SB RAS Common Use Center “Angara” and was supported by the grant No. NSh-6894.2016.5 of the President of the Russian Federation for State Support of Leading Scientific Schools.

\section{REFERENCES}

Adushkin V.V., Kozlov S.I., Petrov A.V. Ecological problems and risks of space-rocket hardware effect on environment Moscow: Ankil Publ., 2000. 638 p. (In Russian).

Bernhadt P.A, Weber E.J., Moorc J.G., Baumgardner J., Mendillo M. Excitation of oxygen permitted line emissions by SF injection into the F region. J. Geophys. Res. 1986, vol. A91, no. 8, pp. 8937-8946.

Biondi Manfred A., Simpler Dwight P. Studies of equatorial $630 \mathrm{~nm}$ airglow enhancements produced by a chemical release in F region. Planet and Space Sci. 1984, vol. 32, no. 12, pp. 1605-1610.

Karlov V.D., Kozlov S.I., Tkachev G.N. Large-scale ionospheric disturbances during the rocket flight with working engine (Overview). Kosmicheskie issledovaniya. [Cosmic Researh]. 1980, vol. 18, iss. 2, pp. 266-277. (In Russian).

Khakhinov V.V., Lebedev V.A., Medvedev A.V., Ratovsky K.G. Capabilities of the Irkutsk Incoherent Scattering Radar for space debris studies. Proc. $5^{\text {th }}$ European Conf. on Space Debris. ESA SP-672. Darmstadt, Germany, 2009.

Khakhinov V.V., Potekhin A.P., Lebedev V.P., Medvedev A.V., Kushnarev D.S., Shpynev B.G., Zarudnev V.E., Alsatkin S.S., Ratovskii K.G., Podlesnyi A.V., Bryn'ko I.G. Radiophysical methods of diagnostics of ionospheric disturbances generated by cargo spacecraft "Progress" on-board engines: Algorithms, instruments and results. Zhurnal Radio-elektroniki [J. of Radio Electronics]. 2010, pp. 555-571. (In Russian).

Khakhinov V.V., Potekhin A.P., Lebedev V.P., Alsatkin S.S., Ratovskii K.G., Kushnarev D.S., Tverdokhlebova E.M., Kurshakov M.Yu., Manzhelei A.I., Timofeeva N.I. Results of remote sounding of ionospheric disturbances during active space experiments "Radar-Progress". Sovremennye problemy distantsionnogo zondirovaniya Zemli iz kosmosa [Current Problems in Remote Sensing of the Earth from Space]. 2012, vol. 9, no. 3, pp. 199-208. (In Russian).

Khakhinov V.V., Potekhin A.P., Lebedev V.P., Kushnarev D.S., Alsatkin S.S. Some results of active space experiments "Plasma-Progress" and "Radar-Progress". Vestnik Sibirskogo gosudarstvennogo aerokosmicheskogo universiteta imeni akademika M.F. Reshetneva. [Bull. of Siberian State Aerospace University named after academician M.F. Reshetnev]. 2013, iss. 5 (51), pp. 160-163. (In Russian).

Lebedev V.P., Khakhinov V.V., Gabdullin F.F., Korsun A.G., Tverdokhlebova E.M., Laletina E.A., Manzhelei A.I. Studying characteristics of plasma surroundings of low-orbit spacecraft. Kosmonavtika i raketostroenie [Cosmonautics and Rocket Engineering]. 2008, no. 50 (1), pp. 51-60. (In Russian).

Mendillo M.J., Hawkins G.S., Klobuchar J.A. A sudden vanishing of the ionospheric F region due to the launch of Skaylab. J. Geophys. Res. 1975, vol. 80, no. 16, pp. 2217-2218.

Mendillo M.J. Report on investigations of atmospherique effecte due to HEAO-C launch // AIAA Pap. 1980, no. 888. pp. 1-5.

Mendillo M., Rote D., Bernhardt P.A. Preliminary report on the HEAO hole in the ionosphere. EOS Trans. Amer. Geopys. Union. 1981, vol. 61, no. 28, pp. 529-530.

Mendillo M., Baumgardner J. Optical signature of ionospheric hole. Geophys. Res. Lett. 1982, vol. 9, no. 3, pp. 215-218.

Mikhalev A.V. Midlatitude airglow during heliogeophysical disturbances. Geomagnetism and Aeronomy. 2011, vol. 51, no. 7, pp. 974-978.

Mikhalev A.V., Ermilov S.Yu. Observation of disturbances of ionospheric emission layers during spacecraft flights. Issledovaniya po geomagnetizmu, aeronomii i fizike Solntsa [Research on Geomagnetism, Aeronomy and Solar Physics]. 
Optical effects produced by running onboard engines...

Novosibirsk: SB RAS Publ. 1997, iss. 107, pp. 206-217. (In Russian).

Mikhalev A.V., Khakhinov V.V., Beletskii A.B., Lebedev V.P. Optical effects of the working onboard engine of the spacecraft "Progress M-17M" at thermosphere heights. Kosmicheskie issledovaniya [Cosmic Research]. 2016, vol. 54, no. 2, pp. 113-118. (In Russian).

Platov Yu.V., Kulikova G.N., Chernous S.A. Classification of gas-dust formations in the upper atmosphere caused by exhausts of combustion products from rocket engines. Kosmicheskie issledovaniya [Cosmic Research]. 2003, vol. 41, no. 2, pp. 168-173. (In Russian).

Platov Yu.V., Semenov A.I., Filippov B.P. Geomagnetizm i aeronomiya [Geomagnetism and Aeronomy]. 2011, vol. 51, no. 4, pp. 556-562. (In Russian)

Potekhin A.P., Khakhinov V.V., Medvedev A.V., Kushnarev D.S., Lebedev V.P., Shpynev B.G. Active Space Experiments with the use of the Transport Spacecraft "Progress" and Irkutsk IS Radar. PIERS Proc. Moscow, Russia, 2009, pp. 223-227.

Tagirov V.R., Arinin V.A., Ismagilov V.V., Klimenko V.V. Unisual optical emission in the atmosphere caused by human activity. $22^{\text {nd }}$ European Meeting on Atmospheric Studies by Optical Methods. Finland., Nurmijarvi. 1995, p. 7.

Vetchinkin N.V., Granitskii N.V., Platov Yu.V., Sheichue A.I. Optical phenomena in near-Earth space during operation of rocket and satellite engines. I. Kosmicheskie issledovaniya [Cosmic Research]. 1993, vol. 31, iss. 1. pp. 93-100. (In Russian).

URL: http://ckp-angara.iszf.irk.ru/html/history.html (accessed by September 5, 2016).

URL: http://atmos.iszf.irk.ru/ru/ground-based/spectr (accessed September 5, 2016).

URL: http://atmos.iszf.irk.ru/ru/ground-based/color (accessed September 5, 2016).

URL: http://videoscan.ru (accessed by September 5, 2016).

URL: http://keoscientific.com/space-science-imagers.php\#SEN-TINEL (accessed by September 5, 2016). 